\title{
A Study on the Effects of Sandplay Therapy on Second Grade Middle School Students with PTSD
}

\author{
Jinfeng Cao* Lizhen Jin $^{* *} \quad$ Chunyu Cui $^{* * *} \quad$ Meiyu Cui ${ }^{* * *}$
}

\begin{abstract}
$<$ Abstract $>$
This study aimed to explore whether sandplay therapy could offer an effective psychological intervention for middle school students with post-traumatic stress disorder (PTSD). We conducted sandplay therapy on six occasions with second-grade middle school students with PTSD and subsequently observed a significant decrease in their PTSD total scores. Our follow-up assessments of the subjects six months later showed that the related indicators remained within an acceptable range. Based on these results, we have concluded that sandplay therapy offers an effective psychological intervention for teenagers with PTSD.
\end{abstract}

Keywords : PTSD, sandplay therapy, psychological intervention, middle school students

\footnotetext{
* CAO, JIN FENG China, Suzhou, Individual psychologist

** JIN, LIZHEN Korea, Namseoul University, Department of Child Counseling and Psychotherapy, master's candidate

*** SUN, CHUN YU China, Yanji, Juvenile psychologist

**** CUI, MEI YU China, Yanbian University, Professor (mycui@ybu.edu.cn)
} 
Journal of Symbols \& Sandplay Therapy, Vol.10 No.1.

\section{I . Introduction}

Post-traumatic stress disorder (PTSD) refers to the delayed appearance and persistent psychological disorder of individuals caused by experiencing, witnessing or encountering one or more actual deaths involving themselves or others, or being threatened by death or serious injuries, or physical integrity being threatened. It will immediately change the environment in which human beings live, and the internal and external balance of individual functions will be broken in an instant. Furthermore, people will fall into a state of emergency. In particular, teenagers find the stress events more difficult to accept and deal with, and these events also bring serious psychological problems to the life of teenagers. Poor handling of post-traumatic stress events in adolescents can lead to serious psychological disorders. External trauma affects not only memory but also body, mood and feeling (Linda \& Daniel, 2007). Therefore, it is particularly important to choose a method to solve psychological problems with high safety, good operability and strong effectiveness. There are many ways to solve the psychological problems of post-traumatic stress disorder. Sandplay therapy can weaken its strong psychological defenses, enhance the openness of teenagers, and show the psychological world through less language expression.

The physical and mental development of middle school students is in an unbalanced period. Their inner world has become very rich. They seldom communicate with their parents and classmates in case of difficulties. Their inner negative emotions gradually increase. The accumulated negative energy leads to the increase of psychological pressure on middle school students and affects their physical and mental health. The nonverbal characteristics of sand table games are well adapted to the psychological characteristics of this age group. Sand table games do not require clients to express their inner thoughts with precise language, hold a non-judgmental attitude towards information, observe the expressions and expressions they show in making sand table works, and wait for changes in the sand table with an appreciative attitude. Sand table games help to regulate the academic mood of middle school students. After sand table games, the scores of middle school students in positive academic emotions increased and those in negative academic emotions decreased. In the sand table game process, 
students can vent their negative academic emotions, reflect their academic mood changes and psychological development process, and effectively enhance their self-confidence (Ke, 2016).

The subject of this thesis was a sophomore in a middle school who was in adolescence. Sandplay therapy is suitable for psychological crisis intervention for clients with PTSD. In this study, sandplay therapy was used as a means to explore the effectiveness of sandplay therapy in alleviating the PTSD behavior of adolescents through the analysis of sandplay works presented by clients with PTSD.

\section{П. Basic theory}

\section{Sandplay therapy}

Jung's analytical psychology emphasizes the concepts of "collective unconsciousness," "prototype" and "prototype image" as well as theories of "complex" and personality types, as well as word association, clinical analysis methods of dream analysis and positive imagination, and "self-nature process" for psychological analysis purposes, which are also important foundations for sand table therapy operation.

Sandplay therapy is a bridge between communication consciousness and unconsciousness. To realize the unconsciousness of content, it needs to arouse the positive imagination of clients. Through making, thinking and repairing, clients can combine them and present them in front of their eyes, finally making self-consciousness strong and returning to the original life track. It realizes the process of psychological energy regeneration of clients. The process of creating a sand table is also a process of combing their hearts. They decide how to put it better. The sand table is probably the symbol of their unconscious prototype. Of course, this must be analyzed in combination with the whole theme of sand tables. At the same time, the attitude and evaluation of clients to the "prototype" is the key to psychotherapy. The individual unconsciousness is mainly composed of various complexes, which is mostly formed by traumatic experiences. Once the complex is activated, it will appear in consciousness from the unconscious 
Journal of Symbols \& Sandplay Therapy, Vol.10 No.1.

state. In this paper, Jung's analytic psychology is used to analyze sand table scenes and intervention strategies.

In Eastern philosophy, one of the more representative viewpoints is the Taoist concept of "keeping balance" between yin and yang and the five elements. Just like the yin and yang levels in the tai chi diagram, achieving a better balance is its goal. They advocate letting nature take its course and governing by doing nothing. Doing nothing is not doing nothing, but acting with respect to the objective law of development of things themselves. Mapping to the sand table, if the obvious things on both sides are basically only placed on one side, it is the embodiment of the psychological imbalance of the clients. For this kind of situation in the initial stage of consultation and treatment, the consultant-led attitude of letting the clients let nature take its course, and the attitude of non-intervention and non-explanation is the embodiment of the Oriental philosophy's attitude of "imitation of nature." Its purpose is to create a "free and protected" space, allowing clients to enter their own world, fully integrated with the sand table, so the healing effect will naturally occur. This invisible protection and guidance enables clients to smoothly display their subconscious mind in the sand table and slowly construct the establishment of self-space, thus realizing the purpose of self-integration. This article is applied to the decoration of sand table works. The first and second sand table works obviously have unbalanced feelings. During the creation of the first three sand table works, the sand table master took an attitude of doing nothing but governing. He was more of a companion, and only when the internalization of the client reached a balanced state did he carry out more intervention treatment.

\section{Post-traumatic stress disorder (PTSD)}

The famous psychologist Hans Selye started from a biological point of view. He suggested that the objective index for determining stress sources should be defined as a physiological variable. In order to detect its effects on individuals, he studied the changes of neurotransmitters after traumatic memory and the degree of brain development in animals combined with the results of psychological component analysis. The corresponding animal models were established. In this paper, the PTSD scale and SCL-90 scale were used to monitor 
the physiological variables of the client, which provided a theoretical basis for the counseling effect.

The cognitive theory of PTSD emphasizes the importance of cognitive adjustment and the extensive impact of traumatic events and their consequences. Clark and others believed that a series of emotions, such as fear, fear and guilt, will persist after traumatic events occur for a period of time, which may lead to disturbance of conscious memory and emotions. According to Janoff-Bulman's shattered assumption, it is the destruction of people's basic beliefs about the world's pre-existence that leads to post-traumatic stress disorder (PTSD).

Domestic metacognitive intervention technology holds that the individual crux of PTSD lies in the rapid formation of strong conditional emotions and automatic operation of PTSD under the circumstances of experiencing or witnessing unusual events of great threat, tremendous impact and pain on individuals. Therefore, it is necessary to construct a set of positive psychological response procedures for individuals with PTSD by using relaxation hinting technology with emotional adjustment as the core, so as to achieve the effect of eliminating symptoms. In this paper, the relaxation hint training method was used to adjust the client's cognitive and emotional responses.

Jungian psychoanalysis is a dialectical relationship between counselors and clients, which is produced with the cooperation of the subconscious. The purpose of Jungian psychoanalysis is to develop the psychological integration of the client. In order to promote this change and make it a conscious process, psychoanalysts try to build a solid bridge between the conscious self and the subconscious. In this case, using the theory of analytical psychology and combining it with the reality of sandplay works from the start of the fourth treatment. The client can actively communicate with their subconscious, adjust and make subconscious changes. It is helpful to improve the effect.

As a psychology founded and developed by Jung, it plays an important guiding role in the development of sandplay, emphasizing the importance of "prototype" in the collective subconscious. In the process of psychoanalysis, exploring the relationship between the structure of the subconscious and the motive force of the consciousness can play a more active role.

Gordon (1999) proposed the following measures for children who had experienced 
Journal of Symbols \& Sandplay Therapy, Vol.10 No.1.

catastrophic events: Provide more information about traumatic events, strengthen the rationality of negative emotions, encourage children to vent and express their emotions, and enhance children's responses. Eton (2000) proposed to establish five forms of intervention systems, including a telephone crisis service, mobile crisis service, petition crisis service, and stress management of serious emergencies.

Erikson's "Drama Creation Test". He allows participants to create dramatic situations for a minute, which are more related to traumatic childhood experiences, real psychological conflicts or problems.

Rose (2003) and others found that a single psychological intervention in PTSD may be ineffective or even harmful in the study of interventions for psychological stress disorder. Sijbrandij (2007) and others have found that behavioral cognitive therapy is effective for patients with acute PTSD in the short term. Marinucci found that sandplay therapy can effectively heal wounds by expressing them and repairing them. Eva Pattis Zoja (2006) led the researchers through experimental research, found that the characteristics of sandplay are different with different mental illnesses, and the consultant's experience determines the correct rate of diagnosis.

Hedda further used the "Small World Test" based on the principle of similarity to compare the characteristics of works presented by adults with different mental illnesses in different countries. There are two factors, age and intelligence, which are used to analyze the characteristics of the subjects. The five evaluation criteria are used to measure whether the subjects deviate from the normal psychological age. However, it is not possible to see which kind of symptoms the subjects belong to. In the same way, Kamp compared the works of ordinary pupils with those of pupils undergoing psychotherapy. He found that ordinary pupils used toys in fewer numbers, types and available areas than pupils undergoing psychotherapy, and the themes were mostly positive scenes.

Sandplay therapy was introduced into China in the 1990s. After that, it has played an important role step by step in psychological counseling. After the Wenchuan Earthquake in 2008, Shen Heyong from South China Normal University led a psychoanalytic worker to establish a mental garden work station in the disaster area. He used sandplay therapy to make 
psychological counseling and growth work for the affected people.

Chen (2009) and others used sandplay therapy to treat bereaved students after the earthquake. They found that after the earthquake, the bereaved students had weak self-recovery ability and poor ability to adapt to the environment. They needed long-term psychological counseling and help. Cai (2010) and others used projection techniques such as sandplay therapy and painting tests to carry out mental health education activities in schools in earthquake-stricken areas on May 12. He enabled the students in the disaster area to effectively express the trauma and repair the trauma, stimulated the creativity of the students, activated the positive strength and healing power of the students, and also reduced the post-traumatic stress disorder (PTSD) and depression to a large extent. The probability of illness and other mental illnesses. Deng (2014) used sandbox therapy to conduct a case study of anxiety among prisoners who were awaiting imprisonment, so that their self-images experienced changes from weak to strong, and the sandplay awakened their self-healing power. These case studies all concluded that sandplay therapy has positive effects. Wang (2016) pointed out in the study that it is widely used for those who are not suitable for language communication, such as children, autistic patients, depressive patients and various psychiatric patients. Lai (2016) found that the effect of individual sandplay was reflected in the process of making sandplay, while the scores for subjective evaluation and objective scale were significantly different after sandplay treatment.

In fact, because of its special playfulness, sandplay therapy has been widely applied by schools for such issues as inattention, learning fatigue, test anxiety, tension between classmates, and tension between parents and children. It also involves students with autism, phobias and somatic psychological disorders. Sandplay therapy not only releases the energy that is hindered internally, but also allows students to communicate with the subconscious to achieve the goal of developing their psychological potential. With the rapid development of sandplay therapy, primary and secondary schools in China now pay more attention to the training of sandplay therapists and the establishment of appropriate equipment.

This study explores a new way of PTSD intervention for middle school students by sandplay therapy, investigates the effect of sandplay therapy on regulating PTSD intervention 
Journal of Symbols \& Sandplay Therapy, Vol.10 No.1.

for middle school students, and analyses the psychological change process of middle school students in sandplay therapy. While adjusting the status of PTSD, it also pays attention to the change of clients' positive emotions.

\section{Research method}

\section{Basic research objects}

The client was a 14 year old boy in the second year of middle school. In the beginning of August 2016, during the summer vacation, the whole family suffered a car accident and the father was killed. The client witnessed the accident. After school resumed, the client's teacher recommended him for psychological counseling.

The client's eyes were bloodshot, haggard, listless, depressed, and he kept silent. Sometimes he responded to questions by nodding his head, repeatedly rubbing or clasping his hands, and he sat on the sofa away from the consultant. The client's mother's reported that the client had experienced nightmares every night for more than a month. After waking up, he was sweating profusely and couldn't sleep again. He was especially afraid of closing his eyes. As soon as he closed his eyes, he unconsciously remembered the car accident and told himself not to think about it, but it was useless. He always felt that he had hurt his father. Before the car accident, not only the client had a particularly harmonious relationship with his parents, but also his parents had a close relationship. At that time, the client's academic performance was the highest level in his class. He had a bright personality and actively participated in class activities. After the accident, the client became silent and did not participate in group activities. He was insensitive to foreign exchanges and very sensitive to cars and rides. The client was reluctant to go to school until the beginning of school. Every time he came to school, he had language and physical conflicts with classmates. His mother said that the physical and mental department of the local tertiary first-class hospital examined her son and diagnosed him with PTSD. 


\section{Differential diagnosis process}

In order to further diagnose the boy's PTSD symptoms, the consultant made a differential diagnosis by using the "PTSD-SS" scale developed by Liu (1998) on the basis of the DSM-IV and ICD-10 and the "SCL-90" scale developed by Wang (1999) for middle school students.

"PTSD-SS" is a self-assessment scale and consists of 24 items. It can be divided into the subjective evaluation of traumatic events (items 1 and 13), repeated intrusion (items 2, 3, 4, 5, 17, 18 and 19), avoidance symptoms (items 6, 8, 9, 10, 16, 21 and 22), heightened alertness (items 7, 11, 12, 15, 20 and 23) and impaired social function (items 14 and 24). The structural validity of the scale was 0.92 . The reliability is 0.86 , with good reliability and validity. Each item is divided into 1-5 grades according to the psychological feelings after the traumatic event. The total score of 24 items is PTSD-SS. The higher the score, the heavier the stress disorder. The results are shown in Table 1 .

Table 1. PTSD-SS Scale Test Results in Pre-Intervention

\begin{tabular}{cc}
\hline PTSD-SS scale & Score \\
\hline Subjective evaluation & 3 \\
Anti-invasion & 22 \\
Repetitive symptoms & 21 \\
Increased alertness & 19 \\
Impaired social function & 7 \\
Total score & 72 \\
\hline
\end{tabular}

Table 1 shows that in this case, the patient's symptoms were diagnosed as PTSD, which is consistent with the diagnosis results of the hospital.

The "SCL-90" Scale for Middle School Students compiled by Wang (1999) and others has 90 items and 10 subscales, namely somatization, obsessive-compulsive symptoms, interpersonal sensitivity, depression, anxiety, hostility, terror, paranoia, psychosis and others. A total of 5 grades were assessed, with homogeneity reliability ranging from 0.6796 to 0.8792 
Journal of Symbols \& Sandplay Therapy, Vol.10 No.1.

and split-half reliability ranging from 0.7029 to 0.8532 , indicating that the 《SCL -90 scale》 for middle school students has good reliability and validity. The higher the score, the more severe the symptoms of the item. The test results showed that although the scores of psychotic causative sub-dimensions were within the normal range, the scores were high, and the scores of other dimensions were significantly higher than those of the normal norm, which indicated that the client was in a stress-sensitive state and lost their living functions after encountering unexpected events. The results are shown in Table 2.

Table 2. SCL-90 Test Results in Pre-Intervention

\begin{tabular}{ccc}
\hline SCL-90 scale & Total average & Norm \\
\hline Somatization & 3.00 & $1.45 \pm 0.45$ \\
Force & 3.20 & $1.72 \pm 0.55$ \\
Interpersonal relationships & 3.11 & $1.74 \pm 0.63$ \\
Depression & 2.92 & $1.55 \pm 0.53$ \\
Anxiety & 3.10 & $1.52 \pm 0.55$ \\
Hostility & 2.17 & $1.70 \pm 0.69$ \\
Terror & 2.14 & $1.39 \pm 0.50$ \\
Paranoid & 2.33 & $1.68 \pm 0.63$ \\
Psychotic & 1.70 & $1.53 \pm 0.53$ \\
Other & 3.28 & $1.57 \pm 0.52$ \\
\hline
\end{tabular}

\section{Description of specific intervention process}

According to the physical and mental development characteristics of middle school students and the characteristics of sandplay therapy itself, combined with the evaluation data of the "PTSD-SS" scale, the intervention plan measures of sandplay therapy were formulated. Once a week, 60 minutes each time, a total of 6 interventions improve the PTSD symptoms of clients. At the same time, it puts forward reasonable goals and suggestions for clients each time, and finally achieves the effect of recovering the normal psychological function of clients. This case is mainly divided into question presentation stages and gets out of the traumatic 
Jinfeng Cao et al. / A Study on the Effects of Sandplay Therapy on Second Grade Middle School Students with PTSD

Table 3. Sandplay Therapy Intervention Process

\begin{tabular}{|c|c|c|c|c|c|c|}
\hline $\begin{array}{l}\text { Intervention } \\
\text { phase }\end{array}$ & Frequency & Consultation objective & Process & Homework after class & Assessment & Time \\
\hline Pre-treatment & Once & $\begin{array}{l}\text { Reduce tension and } \\
\text { anxiety, establish a sense } \\
\text { of security and } \\
\text { formulate intervention } \\
\text { plans and measures. }\end{array}$ & $\begin{array}{l}\text { Check and evaluate the } \\
\text { scale with the consent of } \\
\text { the client. }\end{array}$ & $\begin{array}{l}\text { Teach deep breathing } \\
\text { methods. }\end{array}$ & $\begin{array}{l}\text { PTSD-SS scale SCL-90 } \\
\text { scale }\end{array}$ & \\
\hline $\begin{array}{l}\text { Problem } \\
\text { presentation } \\
\text { stage }\end{array}$ & $\begin{array}{c}\text { First } \\
\text { intervention }\end{array}$ & $\begin{array}{l}\text { Establish a good } \\
\text { consultation and visit } \\
\text { relationship, actively } \\
\text { create a safe and } \\
\text { protected consultation } \\
\text { and visit atmosphere for } \\
\text { the client. }\end{array}$ & $\begin{array}{l}\text { This article introduces } \\
\text { sandplay therapy and } \\
\text { creation of sandplay works. } \\
\text { After the completion of } \\
\text { sandplay therapy and the } \\
\text { creation of sandplay works, } \\
\text { the client is given relaxation } \\
\text { suggestion training to help } \\
\text { them relieve physical } \\
\text { symptoms quickly. } \\
\text { Note: the consultants do } \\
\text { not interfere with the } \\
\text { sandplay works, but only } \\
\text { provide a safe and free } \\
\text { environment. }\end{array}$ & $\begin{array}{l}\text { Practice relaxation } \\
\text { cue techniques. }\end{array}$ & $\begin{array}{l}\text { The scale was } \\
\text { evaluated after the 1st } \\
\text { sandplay work. }\end{array}$ & \\
\hline $\begin{array}{l}\text { Step out of } \\
\text { trauma }\end{array}$ & $\begin{array}{l}\text { 2nd-4th } \\
\text { sessions }\end{array}$ & $\begin{array}{l}\text { According to the results } \\
\text { of the scale and the } \\
\text { situation of the client, } \\
\text { the goal of } \\
\text { out-of-trauma (2nd-4th } \\
\text { sessions) counseling is to } \\
\text { enhance the ability of } \\
\text { subjective assessment } \\
\text { and social function, and } \\
\text { to accept the reality and } \\
\text { find out the } \\
\text { self-development and } \\
\text { change. }\end{array}$ & $\begin{array}{l}\text { Use sandplay works to help } \\
\text { client face up to their } \\
\text { subconscious problems, } \\
\text { slowly get out of the } \\
\text { trauma, and build a safe } \\
\text { world. } \\
\text { Note: In the 3rd treatment, } \\
\text { the empty chair technology } \\
\text { was used to assist in the } \\
\text { emotional transition with } \\
\text { the father. Starting from } \\
\text { this time, intervention } \\
\text { sandplay intervention will } \\
\text { be carried out. }\end{array}$ & $\begin{array}{l}\text { Practice relaxation } \\
\text { cues techniques } \\
\text { Record your changes } \\
\text { every day. }\end{array}$ & $\begin{array}{l}\text { The scale evaluation } \\
\text { was conducted after } \\
\text { the } 4 \text { th session. }\end{array}$ & $\begin{array}{c}\text { Each } \\
\text { consultation } \\
\text { lasted } \\
\text { about } \\
60 \text { minutes. }\end{array}$ \\
\hline $\begin{array}{l}\text { Reconstruction } \\
\text { of life stage }\end{array}$ & $\begin{array}{l}\text { 5th-6th } \\
\text { sessions }\end{array}$ & $\begin{array}{l}\text { The aim of counseling } \\
\text { in the reconstruction of } \\
\text { life (5th-6th times) is to } \\
\text { discover one's inner } \\
\text { strength, learn the } \\
\text { adjustment techniques of } \\
\text { interpersonal relationships } \\
\text { and emotional problems, } \\
\text { and accept real life. }\end{array}$ & $\begin{array}{l}\text { Further use the sandplay } \\
\text { works and adjust sandplay } \\
\text { works to wake up the } \\
\text { client's internal motivation, } \\
\text { thus returning to normal } \\
\text { life. }\end{array}$ & $\begin{array}{l}\text { Practice relaxation } \\
\text { cue techniques. } \\
\text { Record your changes } \\
\text { every day }\end{array}$ & $\begin{array}{l}\text { After the consultation, } \\
\text { a final scale } \\
\text { evaluation was } \\
\text { conducted. }\end{array}$ & \\
\hline Follow up & 1st session & & & $\begin{array}{l}\text { Practice relaxation } \\
\text { cue techniques. }\end{array}$ & $\begin{array}{l}\text { Scale evaluation was } \\
\text { conducted at the } \\
\text { follow-up stage }\end{array}$ & \\
\hline
\end{tabular}


Journal of Symbols \& Sandplay Therapy, Vol.10 No.1.

stage and rebuilds the three stages of life. Please refer to Table 3 for the specific intervention process.

\section{Analysis of Intervention Process of Sandplay Therapy}

1. Analysis of the intervention process of the first session of sandplay therapy

The goal of the first session of sandplay therapy intervention was to establish a good relationship with the client and actively create a safe and protected atmosphere for the client. At the same time, the sandplay therapy process was introduced to the client so that he or she could smoothly create sandplay works.

On September 16, 2016, the client accompanied by his head teacher went to the sandplay therapy room for the first session of sandplay therapy. The client's mental state was very anxious, dispirited and taciturn, and he obviously avoided strangers. The consultant handed over a glass of water before the client took it to the sandplay. After the client received the water, his hands tightly held the cup and he rubbed it repeatedly. He was very nervous and anxious.

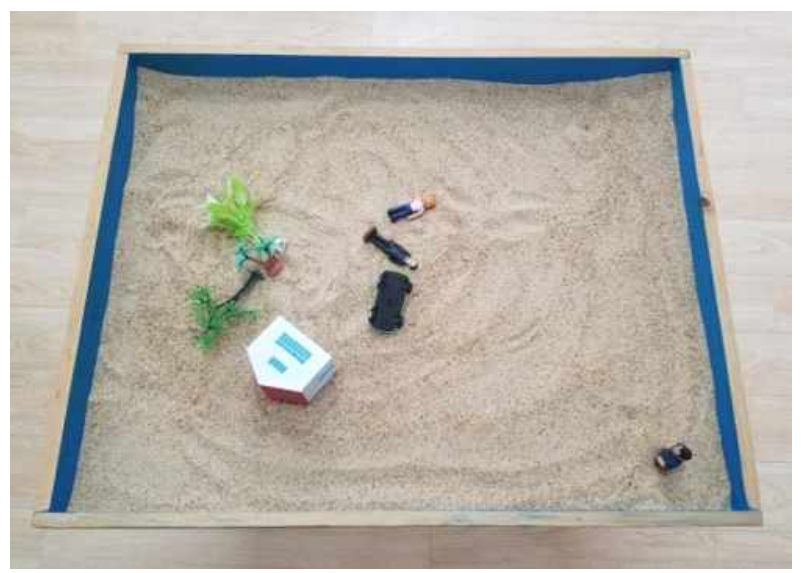

Figure 1. Picture of the first work "Storm" 
The first sandplay work was named "Storm." In this work, trees were blown down on one side, buildings and vehicles were overturned, and several people were scattered beside the blown down trees, creating a chaotic scene. On the other side a man stood alone. The client said: "The sudden car accident destroyed the original good life. I don't want to accept the reality of losing my father. And when all this happens, I can only watch alone on the other side, full of powerlessness towards life." The client wished that the car accident had not happened and the family would return to its former happiness and tranquility. For the family, the father was the support of the family. After the car accident, the family collapsed. In addition, the mother's anxiety and sadness made the client feel a lack of psychological energy.

Plants in sandplay works have symbolic significance of vitality. The trees on one side are blown down and their lives fall down and their growth stops. The vitality of the client can be seen, and the client "protected" and "nourished" are also affected. The overturned car can be understood as the support of the outside world is affected. This work refers to the fact that the father's support power suddenly vanished. There is only one overturned car, which shows that the client's psychological energy is very weak and his heart is chaotic. The car stopped in the work represents that the psychological development of the client had been affected. The collapse of the house reflected the negative psychological state of the client.

The overturned vehicle and the two people lying beside it in the center of the sand table symbolize that the client had a new memory of the car accident, while the two trees collapsed beside it are distorted for the car accident, and the picture he constructed seems to be a forgotten corner in the whole sand table, while the others are watching silently in the distance, showing that the impact of the car accident on themselves is as huge as the named "storm", desperate and helpless.

According to the principle analysis of Eastern philosophy, the client was in an unbalanced state, so in the early stages of sandplay therapy, a natural attitude was adopted to actively construct a free and protected space for the client, so that he could actively release the traumatic experience in the plot, the subconscious mind could slowly influence the state of the client, and the intervention could be more targeted.

According to the problems of avoidance symptoms and increased alertness found in 
Journal of Symbols \& Sandplay Therapy, Vol.10 No.1.

"PTSD-SS" scale before treatment, as well as the lack of psychological energy and the uncomfortable physical state of the client reflected in sandplay, the client was assisted with deep breathing relaxation and muscle relaxation training to help relieve his physical symptoms and emotions. After relaxation training, the client showed obvious relaxation effects. After the first session of sandplay therapy, the client felt more relaxed and made an appointment for the next consultation.

2. Analysis of the second session of the sandplay therapy intervention process

In order to understand the psychological and symptom manifestations of the client more effectively, the second PTSD-SS scale test was conducted with the client before the second session of sandplay therapy intervention. The results had changed. Please see Table 4 .

Table 4. Results of the Second "PTSD-SS" Scale Test

\begin{tabular}{ccc}
\hline PTSD-SS scale & Pre-treatment score & Score of the second test \\
\hline Subjective assessment & 3 & 3 \\
Repeated intrusions & 22 & 19 \\
Avoidance symptom & 21 & 18 \\
Increased alertness & 19 & 17 \\
Impaired social function & 7 & 6 \\
Total score & 72 & 63 \\
\hline
\end{tabular}

Table 4 shows that the subjective evaluation scores had not changed, and other scores had decreased to different degrees. After the first session of sandplay therapy, the client began to face up to the car accident and the departure of his father. He began to face up to the sudden, accidental and destructive accident.

The second session of sandplay intervention aimed at subjective evaluation and the improvement of social function. On September 24, 2016, the client came to the sandplay therapy room alone according to the appointed time. The client was already familiar with the 
operation process of sandplay therapy and the consultant, so his anxiety was relieved. After a brief communication with the consultant, he took the initiative to start the second session of sandplay therapy.

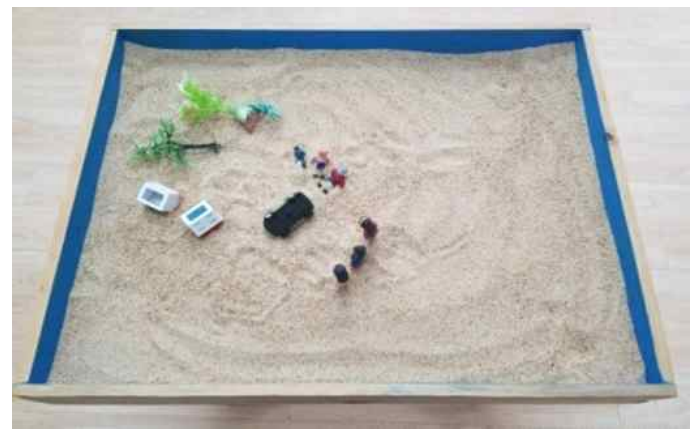

Figure 2. Picture of the second work "After the Storm"

The client's second sandplay work was named "After the Storm." In this work, plants, vehicles and buildings are in a mess and are very dilapidated. However, unlike the first sandplay work, the other side is not alone but accompanied by two or three people. The distance from the scene of the storm has receded, while the people who had been blown down in the storm were sitting quietly and orderly in the storm.

From the creation of sandplay, it was found that the client had begun to step into the "storm scene" step by step and he received constant support from the people around him. Facing the irresistible force in life, you can face it bravely. During the communication, the client said, "I hope my father will be at peace and there will be no more pain and sadness in the car accident."

In the sandplay work, it is found that the client had begun to release his emotions slowly, and the painful experience of traumatic experience had eased somewhat, but owing to the painful experience of parting from his father in the car accident he was still in depression and discomfort. In response to this situation, the consultant used empty chair technology as an auxiliary means to allow the client to talk with his deceased father, to help the client contact his hidden inner feelings, and to make a good start to dialogue with his inner subconscious, so that he could slowly walk out of the huge negative feelings of his father's death and move 
Journal of Symbols \& Sandplay Therapy, Vol.10 No.1.

towards integration and a more positive direction. So as to lay the foundation for a faster return to real life.

In order to improve the effect of subjective evaluation and social function, the consultant assigned the client homework to record his changes every day so that he could learn to observe his changes actively.

\section{Analysis of the third session of the sandplay therapy intervention process}

The objective of the third session of sandplay therapy intervention was to continue subjective evaluation and social function. On September 30, 2016, the client came as promised. He wore a neat striped shirt and looked in a good mental state. After a brief exchange, he began his third session of sandplay therapy.

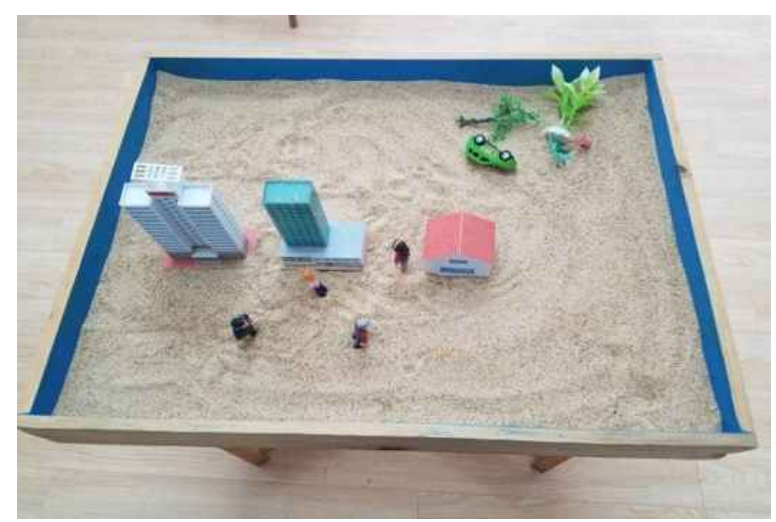

Figure 3. Picture of the third work "Night City"

This sandplay work is named "Night City." The buildings are arranged regularly and there are many tall buildings. People walk in the middle of the buildings and the people walking are isolated and quiet. Trees are scattered on the right periphery of the buildings, and vehicles are scattered beside the trees.

The client explained the work as "everyone walks alone in the city at night. there are many families and stories in the high-rise buildings. the stories of each family are different."

In the sandplay works of the client, he felt that the house gave him a greater sense 
of security, and the client needed to gain strength at home and around him so that his life after the accident could be restored to stability. However, people walk in isolation in the city. Like him, he explained, it was difficult for them to obtain the support of others and families. The plants and vehicles scattered on the periphery symbolize the gradual passing away of the accident experience, gradually scattered on the periphery of life, and gradually isolated from this part. During the conversation, I learned that as his mother gradually recovered from her grief over the car accident and started a new life, the client also found spiritual support from her.

In the process of consultation, the consultant kept communicating with the client's mother, informing the client of the actual psychological condition and teaching them both methods of communication, so that the mother could assist the client to make the consultation effect develop by leaps and bounds.

\section{Analysis of the fourth session of the sandplay therapy intervention process}

The goal of the fourth session of sandplay therapy intervention was to excavate the positive inner self.

On October 7, 2016, the client looked in good mental state and took the initiative to greet the consultant. After a brief exchange, they began to make sandplay games. The client said, "My mother has already found a job and started to supervise my study and homework. The results of the quiz have improved at this stage."

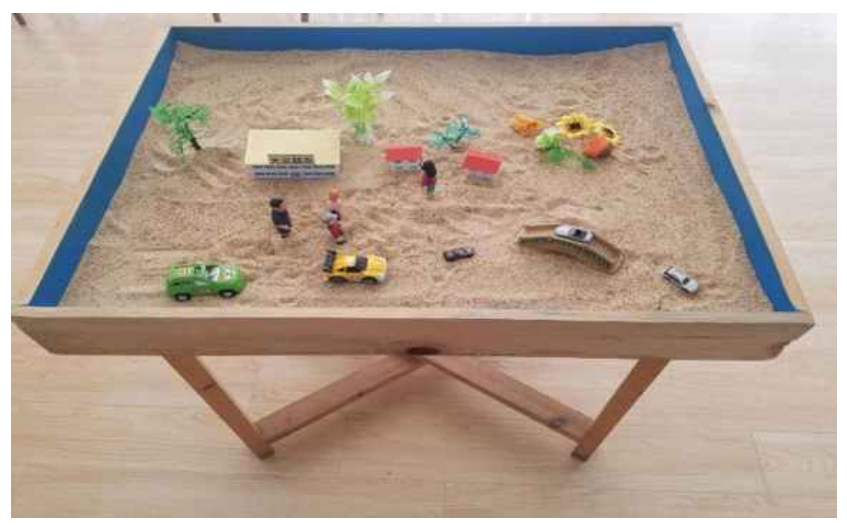

Figure 4. Picture of the fourth work "Future Home" 
Journal of Symbols \& Sandplay Therapy, Vol.10 No.1.

This consultation disturbed the client's current mood, that is, according to the presentation of the first three sandplay works and the application of intervention programs, to make sandplay for the client, entitled "Home in the Future."

From the overall sandplay works, it is found that there are fewer cold high-rise buildings in the city and there is a commercial place, which is interpreted as supply or assistance and comes from the help power of the society. The distance between houses is no longer dense, and green trees and flowers also appear around the buildings. The characters are also scattered in the city, the vehicles are arranged in an orderly way on the periphery of the city, and the means of transportation are often manifestations of self-image. There is a bridge in the corner leading to the lower right, symbolizing the transition of life. The car leaves from the bridge. Green plants blend with urban buildings, showing vitality. The client felt the external threat was reduced, and the characters are scattered, symbolizing that everyone is not alone, but has a place to live and find strength from support. The cars on the periphery also leave the city in an orderly way. In the process of leaving the city, there is a bridge, symbolizing the gradual separation of the two parts through the bridge to rebuild new life and new power. Next, by moving or placing sand tools, the client's inner world was aroused to feel the strength other than his parents' love and activate his inner source of wisdom.

According to the theory of psychodynamics, the physical and mental imbalance of clients caused by unexpected events has begun to slowly ease. The client slowly entered the sandplay to release unconsciousness. At the same time, they realize that they have the ability to slowly shape the world and gradually improve their control over themselves.

Starting from the fourth session of sandplay therapy, the sandplay works presented by the client were actively communicated to enable the client to actively adjust their current psychological state. When the client felt their sandplay attentively and dared to face their sandplay works, the consultant expressed their sympathy to the client, thus stimulating new strength and information from the client. From the perspective of Jungian analytical psychology, the client was helped to build a solid bridge between consciousness and unconsciousness in sandplay works and form a psychological dynamic mechanism. For example, the consultant said to the client, "Where are you in the sandplay?" When asked, the client replied, "I am on the 
left." The consultant said, "What are you doing?" The client said, "Go ahead. Otherwise, what else can you do? Go ahead. If you don't go, you'll be stuck there!" The consultant also said, "Have you decided where to go and how to get there?" The client said, "Let's take one step at a time! I don't know where to go either. I can't stay there." "If you want to adjust the sand in the sandplay, you can adjust or move the sand." After the consultant said this, the client adjusted two people and placed them beside him. The direction of the bridge was adjusted to the upper right corner. Under the bridge there was live water flowing from the lower left to the front right. The two small houses were replaced by a large one and some green plants were added around the houses.

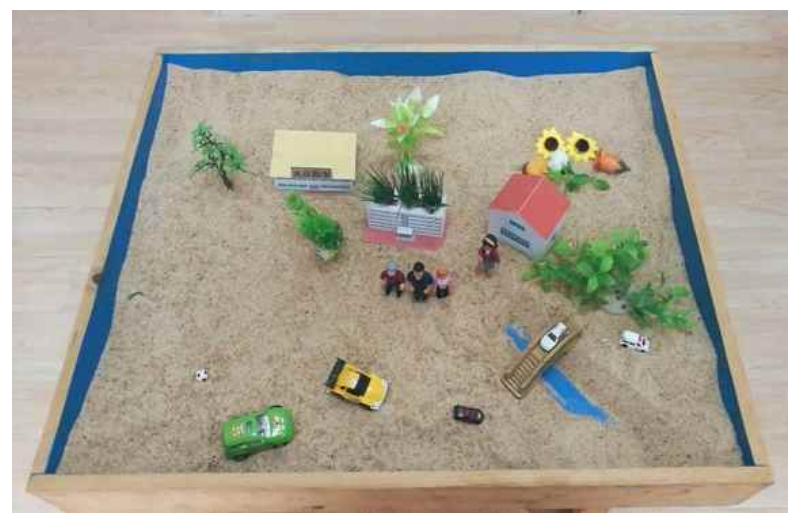

Figure 5. Adjusted picture of the fourth work "Home in the Future"

After the adjustment, the client said, "In fact, there are still many people around me who care about me. I can't go on like this all the time. I feel sorry for myself and they are sad too. I am now the head of the family. I have to bear the burden of starting up. I can't leave my mother alone. What I can do now is to adjust myself, put down this emotion, bury this love in my heart and find myself again." The consultant asked, "Where do you want to put this emotion in the sandplay?" The client said, "I found a football and put it in the lower left corner." The consultant asked, "How do you feel now?"

The client said, wiping away tears, "now I am a little happy, not afraid, not anxious, know what I should do, and turn this love into eternity!" He touched the football while talking. 
Journal of Symbols \& Sandplay Therapy, Vol.10 No.1.

After four sessions of sandplay games, the imbalance of clients was greatly improved, and his internal space and external world were merging.

\section{Analysis of the fifth session of the sandplay therapy intervention process}

The fifth session of the sandplay therapy intervention aimed at rebuilding the social system.

Before the fifth sandplay therapy, the PTSD-SS scale and SCL-90 scale were tested again for the second, third and fourth sandplay therapy effects on the client. The results showed obvious changes. Please refer to Tables 5 and 6 for the results.

Table 5. Results of the third PTSD-SS Scale Test

\begin{tabular}{cccc}
\hline PTSD-SS scale & Pre-treatment score & Second score & Third score \\
\hline Subjective evaluation & 3 & 3 & 2 \\
Counterattack & 22 & 19 & 14 \\
Repetitive symptoms & 21 & 18 & 15 \\
Increased alertness & 19 & 17 & 12 \\
Impaired social function & 7 & 6 & 6 \\
Total score & 72 & 63 & 49 \\
\hline
\end{tabular}

Table 6. SCL-90 Test Results

\begin{tabular}{ccc}
\hline SCL-90 scale & Total average & out of the stage of rebuilding life \\
\hline Somatization & 3.00 & 1.83 \\
Force & 3.20 & 2.00 \\
Interpersonal relationships & 3.11 & 2.56 \\
Depression & 2.92 & 2.08 \\
Anxiety & 3.10 & 1.90 \\
Hostility & 2.17 & 1.83 \\
Terror & 2.14 & 1.71 \\
Paranoid & 2.33 & 1.63 \\
Psychotic & 1.70 & 1.50 \\
Other & 3.28 & 2.14 \\
\hline
\end{tabular}


Tables 5 and 6 show that the first four sandplay treatments had a good effect on the psychological problems of the client, and the PTSD score was significantly reduced, which indicates that sandplay therapy had a good effect on the reduction of PTSD at this stage. The indexes of SCL-90 are also close to the normal range. From the fourth treatment, the client had a strong willingness to change voluntarily. Consultants design dynamic sandplays to intervene in anxiety, hostility, terror, paranoia and other issues. However, the sharing and communication of sandplay works, and the process of carefully caressing the sand, allow the client to find the direction and motivation for progress. This has been proved very well in the mid-term measurement. The following sandplay therapy will be designed and carried out for the social system reconstruction of the clients.

On October 14, 2016, after a brief conversation, the client soon began his fifth sandplay creation. This time during the sandplay creation process, the client was absorbed and their concentration was significantly improved.

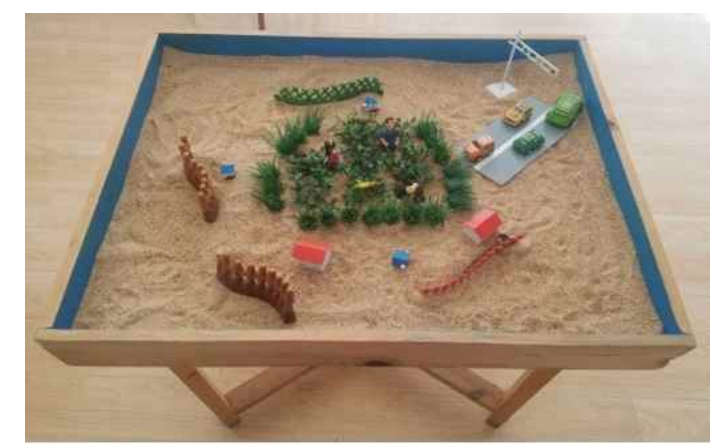

Figure 6. Picture of the fifth work "City Oasis"

The sandplay work is entitled "Urban Oasis." In this sandplay game creation, the client built a green space in the center of the city, with five houses distributed around it, each with a fence beside it. People sat on the ground in the middle oasis, peaceful and at ease. There is a road beside the oasis with three or four cars and traffic signs.

From the perspective of analytical psychology, the oasis shows the vitality of the client. People sit quietly in the oasis, which shows that the client was calm and could gradually accept the fact of traffic accidents. The appearance of traffic signs reflects the client's 
Journal of Symbols \& Sandplay Therapy, Vol.10 No.1.

inner sense of order. The house gives the client enough sense of security, accompanied by alertness and sensitivity. Each house is separated by a fence, which is a barrier to traffic and a sign of boundaries. It shows that each individual and family have a suitable distance and space, calling for new life force in the city as courage to face future life.

By the fifth session of sandplay therapy, the negative emotions of the client to the traumatic events of the car accident and father's death had been well relieved, the positive adjustment of the subconscious structure was obvious, but the interpersonal relationship had not reached the "positive imagination" stage. In response, the consultant set the goal of sandplay intervention therapy as to help the client to actively carry out good interpersonal relationships. During the analysis of the sandplay work, the consultant asked the client, "how do you explain the sandplay work? Is there any need to adjust?" The client replied, "I feel strange and uncomfortable, but I can't tell where it is." The consultant then asked, "Is there anything else in your current life that makes you uncomfortable?" The client replied, "When I chat with others, I always fear that they will look down on me and pity me. I hate that look and that feeling." The consultant asked again, "So your decision is..." Before he had finished speaking, the client replied, "alienate them and sometimes break up with each other. In fact, I don't want to do this." After removing the fence, the client said, "It feels much better to remove the fence now." The consultant immediately said, "Uh-huh, if you feel uncomfortable with others in the future, immediately put down your emotions and learn how to channel them." The client said, "Uh-huh, I know, I'll try."

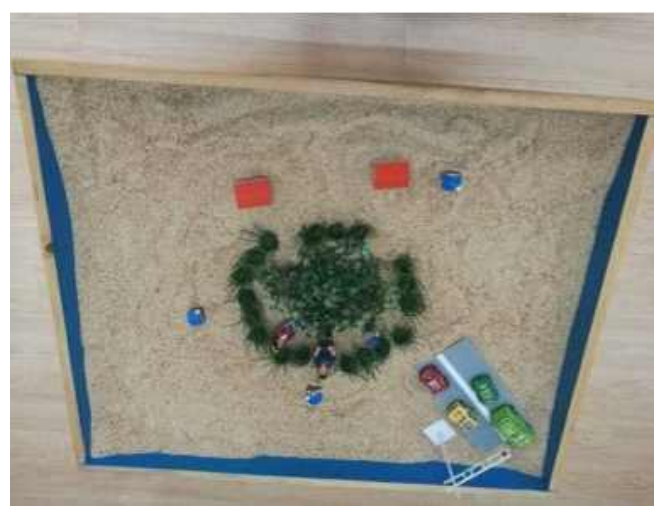

Figure 7. Adjusted picture of the fifth work "City Oasis" 
In this session of sandplay therapy intervention, to adjust the interpersonal relationship problems in the social reconstruction process of the client, especially for the discomfort and emotional problems in the reconstruction of interpersonal relationships, the sand adjustment method was used to reduce the negative emotions of the client in interpersonal communication and other aspects. To further help the client remove obstacles in his heart, arouse more vigorous internal motivation, and achieve certain results.

\section{Analysis of the sixth session of the sandplay therapy intervention process}

The goal of the sixth session of sandplay therapy intervention was to accept the reality, get out of the haze and integrate the real life.

On October 20, 2016, the client was given the sixth session of sandplay therapy as scheduled. The consultant also gave a brief guide stating that the client would soon start sandplay game creation.

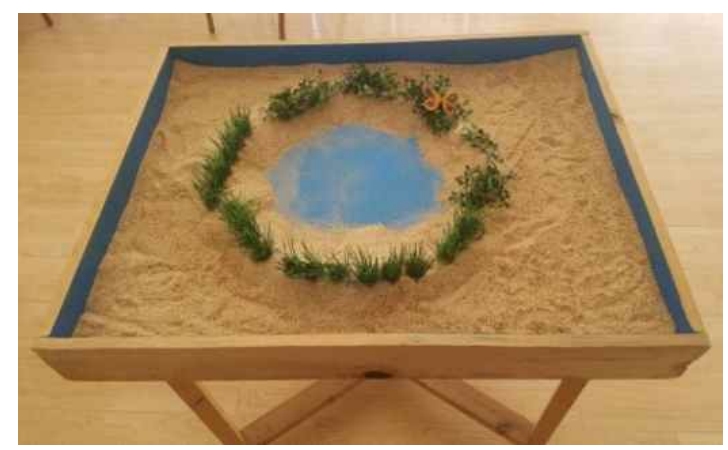

Figure 8. Picture of the 6th work "Calm Lake"

The sandplay work is named "Calm Lake." The biggest feature this time was that it had developed a wide area of water. Using water as a mirror, one could dress properly and feel that the client could face up to everything he was now. The act of opening up the water area was precisely the client's touch and exploration of the unconscious, which allowed the display of the unconscious content. Jung believed that human beings are naturally driven by automatic psychotherapy. When positive emotional experience replaces negative emotional 
Journal of Symbols \& Sandplay Therapy, Vol.10 No.1.

experience, it will blossom everywhere and promote psychological restructuring. The number of sand tools used in the sixth session of sandplay had been greatly reduced. When the client no longer needed to show his complex emotions through more sand tools, his heart would naturally be calmer and he would have more room to accept new life. At the same time, there were green lawns and butterflies around the waters in the sandplay works. Green plants symbolize the power of life, while butterflies bloom again after breaking cocoons and becoming butterflies. This shows that after being hit hard by the car accident, they are like turning cocoons into butterflies to welcome new life and look for new power. The consultant asked about the work, "What does this sandplay scene show?" The client replied, "Um...can I adjust?" He adjusted the water area, built bridges, added a few shells, placed stones on both banks of the river, and adjusted the positions of green plants and insects. The consultant asked, "How do you feel now?" The client replied, "I think it is better now."

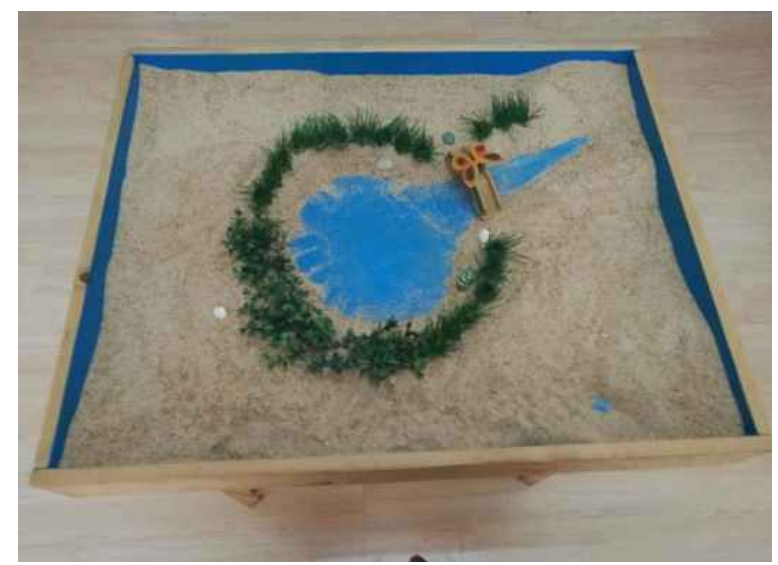

Figure 9. Revised picture of the sixth work "Calm Lake"

With the change of the client's initiative and acceptance of reality, it was a qualitative leap for the client to try to take responsibility. The intervention of sandplay game works and the establishment of the bridge in the modified sandplay symbolize that the client's inner strength had a solid support and source. At the same time, it shows that the client held an open and inclusive attitude towards communication with the outside world, and had achieved the goal specified in the sixth stage. 
In order to describe the indicators of the client more intuitively and to have a smooth end to the sandplay therapy, the PTSD-SS scale and SCL-90 scale were both used to evaluate the effect of the six sessions of sandplay therapy after the sixth session. The results are shown in Tables 7 and 8 .

Table 7. Test results of PTSD-SS scale after sixth session of sandplay therapy

\begin{tabular}{ccccc}
\hline PTSD-SS scale & $\begin{array}{c}\text { Pre-treatment } \\
\text { score }\end{array}$ & $\begin{array}{c}\text { After the } \\
\text { 2nd session }\end{array}$ & $\begin{array}{c}\text { After the } \\
\text { 3rd-4th sessions }\end{array}$ & $\begin{array}{c}\text { After the } \\
\text { 5th-6th sessions }\end{array}$ \\
\hline Subjective evaluation & 3 & 3 & 2 & 2 \\
Counterattack & 22 & 19 & 14 & 12 \\
Repetitive symptoms & 21 & 18 & 12 & 10 \\
Increased alertness & 19 & 17 & 6 & 4 \\
Impaired social function & 7 & 6 & 49 & 35 \\
Total score & 72 & 63 &
\end{tabular}

Table 8. Test Results Before and After SCL-90 Scale

\begin{tabular}{cccc}
\hline Symptoms & Pre-treatment & $\begin{array}{c}\text { Post-traumatic } \\
\text { testing }\end{array}$ & $\begin{array}{c}\text { Post-Reconstruction } \\
\text { Life Stage Test }\end{array}$ \\
\hline Somatization & 3.00 & 1.83 & 1.42 \\
Force & 3.20 & 2.00 & 1.50 \\
Interpersonal relationships & 3.11 & 2.56 & 1.78 \\
Depression & 2.92 & 2.08 & 1.38 \\
Anxiety & 3.10 & 1.90 & 1.40 \\
Hostility & 2.17 & 1.83 & 1.50 \\
Terror & 2.14 & 1.71 & 1.29 \\
Paranoid & 2.33 & 1.63 & 1.67 \\
Psychotic & 1.70 & 1.50 & 1.30 \\
Other & 3.28 & 2.14 & 1.29 \\
\hline
\end{tabular}


Journal of Symbols \& Sandplay Therapy, Vol.10 No.1.

Tables 7 and 8 show that the scores of the client for PTSD symptoms had been significantly reduced, and the indexes of the SCL-90 scale had basically returned to the normal state. Thus, sandplay therapy had a good effect on PTSD intervention. In order to keep the client's expectations and positive attitude towards his normal study and life after sandplay therapy, a return visit after six months was also agreed.

\subsection{Follow-up}

Half a year later, the client was followed up. His mother reflected that the relationship between herself and her son was getting closer and closer. He came home from school to help with the housework and she felt that her child had grown up a lot. The teacher in charge of his class reflected that his academic performance had improved significantly. His attention in class was obviously focused, no longer distracted, and the speed of homework completion was improved. Now he could face the reality of his father's death calmly. He also told his classmates about this experience when he ran for the monitor at the beginning of school. All the teachers were happy for the changes in the client. The peers also responded, and the relationship between the students was very harmonious. He was very willing

Table 9. The results of the SCL-90 scale after follow-up

\begin{tabular}{ccc}
\hline SCL-90 scale & Total average & Follow-up \\
\hline Somatization & 3.00 & 1.33 \\
Force & 3.20 & 1.40 \\
Interpersonal relationships & 3.11 & 2.56 \\
Depression & 2.92 & 1.15 \\
Anxiety & 3.10 & 1.30 \\
Hostility & 2.17 & 1.17 \\
Terror & 2.14 & 0.86 \\
Paranoid & 2.33 & 1.17 \\
Psychotic & 1.70 & 0.80 \\
Other & 3.28 & 1.14 \\
\hline
\end{tabular}


to help the other students. The client had become better integrated and started a new life. Finally, the SCL-90 scale was tested, and the results showed that all the indicators were within the normal range. The anxiety, depression and interpersonal relationship index had decreased compared with the end of counseling. The results are shown in Table 9.

\section{Conclusion}

In this case, a client with PTSD symptoms was diagnosed through PTSD-SS scale. After six sessions of sandplay therapy, the results of the PTSD-SS scale and SCL-90 scale showed significant changes in all dimensions. Sandplay therapy had a significant effect on the client with PTSD symptoms, and the return visit after half a year showed very good results. This shows that sandplay therapy is not only effective in treating PTSD symptoms, but also conducive to the emotional improvement and physical relaxation of adolescent clients to a certain extent. Sandplay therapy is conducive to the release of negative emotions of clients and has obvious intervention effects.

1. Through observing and recording the performance in the sandplay therapy process, the analysis of sandplay works, the use of sand and the theme changes of sandplay works, it was found that the client's sandplay works were changing in a positive direction. With the progress of sandplay games, the combination of sandplay therapy and auxiliary technology had better therapeutic effect on the client's PTSD symptoms. The client expressed his feelings by sandplay works without being restricted by nonverbal process, thus promoting his psychological growth.

2. The consultant's company in the creation of works made the client feel protected and enjoy a free space atmosphere, and conveyed the strength of support and empathy, thus achieving the goal of healing. Through interviews with the client's parents, class teachers and classmates before and after sandplay therapy and the observation of the client by consultants during sandplay therapy, it was found that the client's negative emotions were vented in 
Journal of Symbols \& Sandplay Therapy, Vol.10 No.1.

sandplay therapy, self-confidence was improved in creation, positive energy was continuously increased, and this energy was transferred to daily life.

This study found that sandplay therapy is an effective psychotherapy technique for PTSD symptoms. Furthermore, it is also in line with the psychological development characteristics of the client. When PTSD symptoms cannot be smoothly expressed by individuals, sandplay therapy is effective in understanding the psychological state of students.

\section{References}

An, F. (2010). Influencing factors analysis of post-traumatic stress disorder in the Wenchuan earthquake-related military rescuers, Fourth group medical school; Master's Thesis.

Chen, C. R., Shen, H. Y. (2006). Sandplay production of students with lost relatives in earthquake.

Deng, W. (2014). Sandplay therapy process and effect on released prisoners. Psychological Skills and Applications, 7, 31-35.

Fu, C. Q. (2008). Foreign intervention models of post-traumatic stress disorder and enlightenment.

Han, J. B., Liu, L. F. (2003). A follow-up study of post-traumatic stress disorder in 105 patients after traffic accidents. Social Behavioral Psychology. 6 (10), 840-842.

Jin, H. Y., Wang, Y. F., Wei, X. X. (2013). Cognitive psychological intervention: Effective Solution to Mental Illness, Learning Disabilities and Personality Disorders. Shenyang: Liaoning Science Press.

Li, C. Q. (2006). Symptoms and intervention strategies of PTSD in Children. China Special Education, (6), 88-91.

Liu, X. C., Ma, D. D., Liu, L. Q. (1998). Development of the post-traumatic stress disorder self-rating scale and its reliability and validity. Social Behavior Science. 7 (2), 92-96.

Luan, M. H., Li, W., Li, J. M. (2014). Research progress of posttraumatic stress disorder.

Niu, L., Wang, H. R., Wu, Y. M., Pan, S. M. (2013). Research progress of posttraumatic 
stress disorder in children. Shenyang: Liaoning Science and Technology Press.

Shen, H. Y. (2011). Sandplay therapy. Beijing: China Renmin University Press.

Sijbrandij, M., et al. Treatment of acute posttraumatic stress disorder with brief cognitive behavioral therapy: A randomized controlled trial. American Journal of Psychology, 2007. 164: 82-90.

Wang, J. S., Li, Y., He, E. S. (1999). Development of SCL-90 in secondary school students.

Wang, P., Huang, G. (2007). Research progress of sandplay in clinical psychological assessment

Wang, S., Zhang, Z. J., He, J. F. (2009). On the psychological intervention strategies of children's post-traumatic stress disorder of psychological intervention strategies.

Xu, G. X. (2010). Case study on psychotherapy and trauma. Shanghai: Shanghai Education Press

Zhang, X. M., Xu, G. X., Lin, R. F. (2011). The application of sandplay therapy in the field of child psychotherapy. 